This is the author's postprint version of: Verpoorten, D., \& Westera, W. (2014). Structured reflection breaks embedded in an online course - Effects on learning experience, time on task and performance. Interactive Learning Environments. DOI:10.1080/10494820.2014.910531

\title{
Structured reflection breaks embedded in an online course - Effects on learning experience, time on task and performance
}

\begin{abstract}
The purpose of this paper is to gain insight into the effects of practicing short, frequent and structured reflection breaks interspersed with the learning material in a computer-based course. To that end, the study sets up a standardised control trial with 2 groups of secondary-school pupils. The study shows that, while performance is not affected by these embedded "reflection rituals”, they significantly impact time on task and perceived learning. The study also suggests that the exposure to such built-in opportunities for reflection modifies the engagement with the content and fosters the claimed readiness for application of a similar reflective approach to learning in other occasions.
\end{abstract}

Keywords: reflection breaks; reflection prompts; reflection support; online formal learning; self-instruction; embedded prompts; learning dashboard; data mirroring; student sets the test strategy; pausing principle; self-assessment; feeling of learning; time on task; meta-cognitive training; Liferay; portlets; evolutionary psychology.

\section{Introduction}

Educating the knowledge workers of tomorrow demands to simultaneously foster the mastery of domain content and the development of transversal (domain-independent) skills (Egan, 2010). The latter empowers individuals to cope with requests for new knowledge acquisition and ongoing personal development (Brown, Lauder, \& Ashton, 2008; Fredriksson \& Hoskins, 2007). For providers of initial instruction, this responsibility to prepare students to be mindful, engaged and responsible learners in a lifelong learning society is not a trivial one (Laurillard, 1993; McGuiness, 1999). It implies finding ways to help students to learn how to become 
expert students (Ertmer \& Newby, 1996) or to act as "reflective practitioners” (Schön, 1983) or to acquaint with deep learning (Entwistle, 2001), in their daily duties as learners already.

To practice "split screen teaching” (Claxton, 2006), that is maintaining a dual focus on the content of the lesson and the learning processes and dispositions that are in play, is difficult. Tutors can perceive thinking skills training as consuming the time available to “cover the material” (Gill \& Halim, 2006). Tutees are often unsure about what reflecting is, how they are expected to reflect in their scholarly duties (McKenzie, 2009) and more fundamentally why reflection is a condition for high-quality learning. For instance, Weir (1998, p. 458) describes that his students view reading as "a passive experience of running their eyes over print, then hoping that they'd 'got it' only to find, when faced with comprehension questions after reading, that they had not”.

The challenge is therefore to devise reflective methods and tools which do not consume teaching time while making students cognizant of what it can mean to incorporate reflection in learning (Loughran, 1996). This paper precisely probes the potential of short reflection breaks to stimulate meta-cognitive awareness of reflective processes. The approach includes a standardised controlled experiment with a total of 40 test persons (secondaryschool students).

\section{Reflection breaks}

Reflection breaks - also called "pausing principle” or "pause procedure" - have received attention from research (for a systematic review, see Parker, 1994) when applied to face-toface lectures (Rowe, 1976, 1986; Simpson, 2004) and mainly in relationship to student retention.

In an early study, Di Vesta and Smith (1979) interspersed a 21-min lecture with three 2-min breaks occuring at 7-min intervals. During these breaks undergraduate students were asked to perform either an irrelevant puzzle, an individual review of the notes, or a group discussion. The latter option produced the best recall. A study by Ruhl, Hughes and Schloss (1987) compared lectures presented without pauses to lectures where, every 12/18-min, the instructor asked students to pause. During the pauses students worked in pairs to discuss and rework their notes. Students prompted to make such discussion/reflection breaks showed a better long term performance on free recall. Chi, De Leeuw, Chiu, and Lavancher (1994) asked students to pause after each sentence of a passage on the human circulatory system and self-explain what the sentence meant. The prompted group had a greater gain from the pre-test 
to the post-test. Moreover, prompted students who generated a large number of selfexplanations (the high explainers) learned with greater understanding than low explainers.

To the exception of a book exalting the value of pausing for improved... leadership (Cashman, 2012), literature does not deliver much recent research work on reflection breaks, at least labelled as such. The closest contemporary strand of research might be the one revolving around "testing effect” (Butler, 2010) and “active recall” (Karpicke, Butler, \& Roediger, 2009) which also embeds stop-and-think beacons (mostly administered as tests) in the learning flow to stimulate retrieval processes. Affinities can also be found with the reading/writing-to-learn movement (Fulwiler \& Young, 2000).

The present study differs from the previous ones in that it: a) institutes contrasted kinds reflection breaks in an online context of self-instruction, b) looks towards metacognitive training and academic literacy development, c) documents perceptual and attitudinal effects of reflection breaks besides the regular impact on learning outcomes.

\section{Hypotheses}

Three hypotheses guided this study:

Hypothesis a - The confrontation with reflection breaks (RBs) affects the perception of the learning experience, including students' consciousness that reflection is relevant for learning. Hypothesis b - Because of the brevity of RBs, the time spent in the course does not significantly differ between treatment and control group.

Hypothesis c - The treatment group, benefiting from the RBs, gets a better score at the final performance test compared to the control group.

\section{Method}

In order to put at the test the infusion of short and structured reflection affordances, a comparative study was set up based on an online course delivered at 2 different conditions: with and without RBs. The intervention variable was the exposure to RBs. Consistently with the hypotheses, the dependent variables were accounts of learning experience (hyp. a), time spent in the course (hyp. b), and score at the final test (hyp. c).

\section{Participants}

The sample consisted of 42 secondary-school pupils physically present in computer rooms during the experiment. Pupils came from a secondary-school in the area which expressed 
interest in participating in experiments as fieldwork and external projects. These pupils attended preparatory scientific education in view of an access to higher education.

Half of the subjects were assigned to the control group and half to the treatment group, according to a random distribution performed beforehand and based on the alphabetical class roll received from the school. Two students who missed either the pre- or the postquestionnaire were removed from the analysis, leaving 40 test persons (mean age $=17$ years old) in the final sample: 21 participants (9 females) in condition 1 (plain course, control group) and 19 (6 females) in condition 2 (course equipped with RBs, treatment group). Participants received a 15 euro iTunes voucher for their participation.

\section{Apparatus}

\section{Course}

The learning material selected for this experiment was a shortened version $(1 \mathrm{H})$ of the 4-hour online course "Sex and the Evolution" (CCC \& GGG, 2007), offered by the University of PPP. The course covered non trivial and interrelated notions and mechanisms as defined by Darwin and his followers: reproductive value, paternity uncertainty, mating strategies, differential investment in parenthood, etc. The course invited learners to use this theory as an interpretation grid of gender-related behaviours observable in everyday life. The course was made of 5 chapters of 5 pages each, while each page contained about 200 words and one or two illustrations (Fig. 1). In order not to bias the use of the different RBs (see next section) by uneven levels of difficulty in the content, special attention was paid to ensure equivalence between all chapters. Each of them underwent the Flesch reading ease test (Flesch, 1948). The test returned a comprehension difficulty level between 48 and 55, which makes the content comparable to the level of the "Time" news magazine (52). A systematic concept mapping procedure of each chapter additionally ensured that they presented an even level of complexity regarding the number of new concepts introduced.

\section{<FIGURE 1 NEAR HERE $>$}

Tools

The reflection breaks. The study exposed participants to 3 types of breaks meant to give a face value to reflective processes beneficial to the mastery of the learning material: 
(1) questioning: previous research highlights the importance of encouraging students to generate questions about the study material (Logtenberg, van Boxtel, \& van HoutWolters, 2011; Marbach-Ad \& Sokolove, 2000; Pedrosa de Jesus \& Moreira, 2009). In this study, students deliberately and systematically exerted a questioning strategy called "student sets the test". Participants were requested to formulate questions that they might envision to be raised at the exam. Doing so, they put themselves metaphorically in the shoes of a teacher composing a test. The "Question break" (Fig. 2a) offered a note-taking tool where students wrote their questions down. (Participants to the control group were allowed to take electronic annotations in the simple text editor “Notepad”).

(2) evoking: an evocation brings or recalls to the conscious mind what has been previously read. Conceptual works of the "mind management" theory (BrownFrossard, 2012; La Garanderie, 1989) suggest that this process of mental imaging allows readers to transform what they have read into a mental object (Seel, 2001; Vermersch, 2009) and thereby anchor it in their mind. According to these authors, it is intellectually essential to do this evocation, otherwise the learning experience remains in the sensorial context of the reading and does not enter the mental realm. The "Evocation break" combined an "I start the evocation" button and an "I stop the evocation” button (Fig. 2b).

(3) self-assessing: research shows that self-assessment can lead to significant enhancements in learning (Taras, 2002) by developing students' habit to evaluate the strengths and weaknesses in their own study. According to Nicol and MacFarlaneDick (2006), in order to develop this habit and capacity, courses must offer opportunities for judging one's own level of understanding and mastery of learning material”. The "Self-assessment break" presented as a 5-star visual scale (Figure 2c) that the students used to indicate their current level of mastery of a defined portion of content. For each level a standardized explanation was given: a) I do not understand what this text is about, b) I can identify the main idea in the text but there are still things I do not understand, c) I fully understand the text: main idea and details, d) I could make a summary of this page while having it on the screen, e) I could make a summary of this page without looking at it. 
Technically speaking, the RBs were created as miniature Web applications or "portlets” (Fig. 2) deployed on the eLearning platform Liferay. Each of them condensed, in a clear and identified graphical style, a single interaction point designed to support one of the reflective processes (questioning, evoking, self-assessing) to apply on the first-order activity (studying the content of the page).

The subjects had to deliberately practise one RB per page visited (or re-visited). As shown in Table 1, pupils got acquainted with one type of RB in each of the 3 central chapters: on all pages of Chapter 2, only the "Question break” was available, on all pages of Chapter 3, only the "Evocation break" was present and on all pages of Chapter 3, only the "Selfassessment break” was displayed.

\section{$<$ TABLE 1 NEAR HERE $>$}

All pages of Chapter 1 were devoid of any RB. It means that the treatment group studied this chapter exactly as the control group did: without any RB. This arrangement opened to participants a possibility of contrast within the learning experience and provided an internal yardstick to the chapters studied with support tools. On the opposite, all pages of Chapter 5 exhibited the 3 RBs. The choice of any of them was left on each page to the pupils, based on their experience gained in the previous chapters.

The reflective tooling was implemented in accordance with the basic design principles for effective meta-cognitive instruction as synthesized by Bannert (2006):

- the integration in the subject matter: the "technical agility" of the portlets allowed a placement contiguous to the learning material;

- a straight explanation of the usefulness of each instructed strategy: the pedagogical rationale underlying each $\mathrm{RB}$ was given to the students in the course, at the entrance of the specific chapter wherein they had to use it. This rationale was stated in a wording very similar to the one given above, in an effort to let students benefit from explicit pedagogical knowledge;

- the provision of a sufficient training time or use frequency: the assignment requested a systematic use of the RB at a relatively high frequency.

The Learning Dashboard. In order to consolidate the systematic reflective approach (one page/one RB) fostered in the course, a “learning dashboard” (Fig. 3) was also set up. A colour 
scheme indicated whether or not the amount of (re-)visited pages matched the amount of RBs' activations. In case of match, the number appeared in green and in case of discrepancy in red.

\section{$<$ FIGURE 3 NEAR HERE $>$}

\section{Instruments}

The data sources for this study were the returns from the questionnaires (pre, post, follow-up, teacher judgment) and the logging data.

Pre-questionnaire. Taken prior to the course study, this questionnaire evaluated the students' pre-knowledge of the course topic with 6 multiple-choice questions (see Appendix A).

Teacher judgement. Considered as the persons having the most comprehensive view on individuals, the principal teacher of each pupil was asked to empirically rate their reflective capacity. To this end, the 2 concerned teachers were presented an electronic questionnaire with the list of their pupils and 3 options: high/medium/low ability for reflection. More elaborated existing instruments such as the Metacognitive Awareness Inventory (Schraw \& Dennison, 1994), which comprises 56 detailed questions, were not practical within the context at issue.

Post-questionnaire. Taken after the course completion, this questionnaire collated:

- an evaluative feedback: open and closed questions collected student's perceptions of overall satisfaction, sense of control, and feeling of learning. Questions relating to the instructional intervention were added for the participants to the treatment group.

- a performance measure: a test assessed the knowledge and comprehension (see Appendix A). Ten multiple choice questions were selected among a pool of questions tested in a previous run of the course. The discrimination index of the test items was of .67 in average, which is a medium-high level of difficulty (McAlpine, 2002). In 3 open questions, students were additionally asked to analyse and explain a picture with the notions they learnt in the course. This was consistent with the design of the course that carefully displayed selected illustrations on each page (Fig. 1).

Follow-up questionnaire. The follow-up questionnaire was administered one month after the completion of the course. Pupils were asked to give to an imaginary friend who ought to take 
the same course advice regarding relevant study strategies to apply. The reflective strategies experienced in the course (after each page, imagine a question that you might have at the exam on this content - RB1 Questionning / after each page, make a break to carefully think about what you have just read - RB2 Evoking / after each page, assess your current mastery of this content - RB 3 Self-assessing) were provided. The perceived relevance of the strategies was rated by pupils with sliders on 100-point scales, an asset available on the survey software Qualtrix. In order to compare the judgements about the strategies offered in the experiment with a wider range of reflective strategies, pupils were asked to judge the relevance of 3 alternative strategies (Verpoorten, Westera, \& Specht, 2011a) foreign to the experiment (after each page, make a short summary thereof / read each page twice / take enough time to also understand the details in each page).

Logging data. The tracked data was the time in the course (total and per chapter), the number of pages visited (total and per chapter) and the number of times a RB was used. The logs also stored the choices made by learners in Chapter 5 regarding the reflection breaks.

\section{Procedure}

After the pre-questionnaire, the subjects studied in one version of the course (with or without RBs) on an individual computer. Everyone was evenly invited to practice a thoughtful study freed from time pressure in order to gain as much mastery as possible of the learning material. Emphasis was put on this mastery-learning in the initial instructions and the invitation to practice it was equally repeated at the start of each content chapter in both groups. However only the treatment group benefited from a "tooling" (the RBs) to put this mindful and alert approach into practice. After the course completion, students filled in the post-questionnaire and were invited to keep busy with brain games until all students left the premises altogether. The researchers were physically present from the start to the end of the experiment. Apart from a short welcome speech and some technical guidance for the opening logging process, they had no intervention. The follow-up questionnaire was sent to each participant one month after the experiment in order to evaluate possible persistent effects.

\section{Results}


Students in both groups yielded a mean score of 1.5 points out of $6(S D=1)$ in the prior knowledge test. T-test showed that groups were comparable, $t(38)=1.22, p=.22, d=0.38$. The ability levels to reflect, as rated by the teachers, were evenly distributed in the 2 groups, $U=29, p=.83, r=.09$

\section{Logging data}

Tracked data confirmed that both groups covered the whole course and that the treatment group performed the reflective assignments with diligence. For this group, the average ratio page views/RBs was close to the perfect fit $(M=0.93, S D=0.1)$. In Chapter 5 , the interaction footprints revealed the choices of students: the "Question break" and the "Evocation break" represented 32\% of the reflective enactments and the "Self-assessment break" 36\%.

\section{Feedback from learners}

Hypothesis a: The provision of RBs affects the perception of the learning experience, including students' consciousness that reflection is relevant for learning. Based on the follow-up questionnaire, the treatment group recommended more cheerfully ( $X=68 / 100$ on the slider) the use of the "Question break" than the control group ( $X=51 / 100)$. This is the only significant difference, $t(28)=4.81, p=.03, d=.15$ that emerged from the 29 answers received (14 from participants to the control group and 15 from the treatment group). However, results showed a tendency for the treatment group to advise the 2 other practiced reflection breaks ("Evocation" and "Self-assessment”) with a higher intensity (Fig. 4). The other thoughtful learning strategies suggested (writing the keywords of the page, summarizing the page, taking enough time to understand in detail) were summed up and also returned a slightly higher intensity of recommendation in the treatment group (Fig. 4).

\section{$<$ FIGURE 4 NEAR HERE $>$}

In terms of contrast with regular learning experience, $73 \%$ of the treatment group claimed that their learning experience in the course differed from usual, against $61 \%$ in the control group. Since these proportions seemed quite similar, a closer look the reasons given for this perception exhibited that $89 \%$ of the treatment group explicitly linked it to the practice of reflection while the dominant reason given by the control group was the habit of taking handwritten annotations (46\%), as opposed to annotations on the computer. 
The acquaintance with the reflective approach as practised in this experiment emerged from a question probing prior familiarity with the 3 RBs. All were declared "almost never" practised by about half of the sample (Fig. 5).

\section{$<$ FIGURE 5 NEAR HERE $>$}

In terms of perceived effect on time and mindfulness, the RBs were rated by the students (Fig. 6) on a 3-point Likert-type scale for their contribution to their study result and study time ( 1 = decreased the quality of my study/my study time, $2=$ did not affect the quality of my study/my study time, 3 = increased the quality of my study/my study time). A majority of students developed the impressions that RBs concurrently contributed to a mindful study and to an inflation of study time.

\section{$<$ FIGURE 6 NEAR HERE $>$}

For the question about perceptions of the global learning experience, Mann-Whitney tests detected a higher level of perceived learning $U=115, p=.01, r=.39$ in the group prompted to reflect $(M d n=4)$ than in the control group $(M d n=2)$. Tests conducted on the satisfaction towards the course (Mdn = 4 for both groups) and sense of control ( $M d n=3$ for both groups) did not produce tangible differences between the groups, respectively $U=151, p=.13, r=.23$ and $U$ $=164, p=.3, r=.16$

Time on task

Hypothesis b: The provision of RBs does not impact total time in the course. Total time on task (Fig. 7) was descriptively higher in the group prompted to reflect ( $M=52 \mathrm{~min}, S D=9$ min) than in the group without prompting ( $X=26 \mathrm{~min}, S D=12 \mathrm{~min}$ ), and the difference was significant, $t(38)=7.46, p<.0001, d=2.45$.

\section{$<$ FIGURE 7 NEAR HERE $>$}

\section{Performance}


Hypothesis c: The provision of RBs improves scores at the test. Analysis of the performance scores for the multiple-choice questions revealed no significant differences between the control group $(X=4.5, S D=2.24)$ and the treatment group $(X=4.7, S D=1.59), t(38)=.41, p$ $=.67, d=.08$. A 3-level scoring rubric was used to control the quality of the answers to the 3 illustrated open questions: trivial explanation of the picture - explanation invocating the correct Darwinian concept - explanation contextualizing the correct Darwinian concept in the overarching evolution theory. The treatment group $(X=4.5, S D=1.6)$ did not perform differently from the control group either $(X=3.7, S D=1.7), t(38)=1.54, p=.13, d=.05$.

\section{Discussion}

\section{Hypothesis a (perception of the learning experience and the importance of reflection)}

Because RBs aroused thinking while learning in a rather unusual manner, their influence was expected to be on the global perception of the learning experience and the importance of reflection. The data supports this hypothesis. It even suggests that the chief pedagogical achievement of the RBs lies in the awakening of a different attitude to reflective practice.

The awareness that being mentally engaged makes sense while learning can be mapped onto the taxonomy of affective domains elaborated by Krathwohl, Bloom, and Marcia (1964) to organize levels of commitment and concern. Five levels (receiving / responding / valuing / organization / characterization by value) describe the internalization process whereby a person's affect toward an object (here, reflection) passes from unawareness of its existence to a point where the affect is "internalized" and consistently guides or controls the person's behaviour. The entry point to this consciousness continuum ("receiving”) consists in becoming aware of or sensitive to the existence of certain ideas, material, or phenomena and being willing to tolerate them. The findings of this study suggest that students in the treatment group have hit this level after a rather short exposure to RBs: they recommend them with more intensity than the control group (see section "Follow-up questionnaire” and Fig. 4) as relevant to regular study. This finding could also be interpreted according to Boud, Keogh, and Walker's theoretical model of reflection (1985). This work delineates 4 major outcomes to the practice of reflection in education: a) new perspectives on experiences, b) readiness for application of these new perspectives in future experience, c) 
commitment to the task, and d) change in behaviour. The current study brings indications of benefits with regard to $a$ and $b$.

The study also allows questioning the place of thinking skills in regular classroom practice. Results show that the 3 offered reflective techniques in the course (questioning, evoking, and self-assessing) are fresh to half of the students in each case (Fig. 5). One can appraise this percentage as low with regard to the fact that the 3 RBs instantiate basic operative processes of quality academic habits. This finding is in agreement with another experiment (Joseph, 1999) evidencing that 36\% of the students report a lack of cognitive activity when reading a textbook and 38\% note that they do not try to evaluate their understanding after reading a selection. The atypical character of the systematic meta-cognitive awareness training, as given by RBs, also surfaces the qualitative data (see "Contrast with regular learning experience”). It seems possible that the confrontation with the RBs while learning transforms reflection as a learning experience on its own.

\section{Hypothesis b (time on task)}

Because RBs were conceived as lightweight reflection techniques, it was foreseen that they would have no significant impact on the time spent in the course. Hypothesis b is not confirmed: study time is strongly affected by the presence of RBs. This result calls for additional considerations.

Thanks to the improved tracking facilities available in this study, logging data reveals that the additional time spent in the course by the subjects in the treatment group cannot be imputed to the time they spent using the RBs. For instance, the logging data of Chapter 3 exhibits that the time spent on the "Evocation break" accounts for only 25\% of the total time spent in this chapter. The "Self-assessment break" used in Chapter 4 is probably even less time-consuming, at least with regard to the requested action (ticking a level of mastery). This additional time spent in the course is the most intriguing finding of this study. It calls for further clarifications of the relationships between prompted reflection and time on task.

A possible explanation is that the RBs stimulate a different learning attitude and commitment towards the studied material. The structured reflection slots arranged in a course would not per se impact the time spent studying but the reflective orientation that they infuse would.

\section{Hypothesis c (performance)}


Because the controlled introduction of structured opportunities for reflection was intended to support a quality internalization of the content, it was anticipated that the group benefiting from these artefacts would get a better score at the final test. Results do not support this hypothesis, even with secondary school pupils who might be seen as still partially unformed regarding learning skills and therefore likely to benefit from training. While disappointing, this result is not uncommon (see for instance Chiazzese et al., 2006; Thompson, 2009; Verpoorten, Westera, \& Specht, 2012; Verpoorten, Castaigne, Westera, \& Specht, 2012).

The lack of impact sounds nevertheless as a counterintuitive finding. A large literature extols the advantages of reflection for learning. Received wisdom would be prone to say that frequent call to reflection leads to better achievements. The results of the present study remind that the theoretical benefits of various scaffolds do not match their actual impact on performance. The earnest instruction in reflective strategies and even students' expressed perception of their usefulness do not automatically lead to higher achievements. Although test performance is not the single measurement of learning effect (Boud, 1990), it should reasonably reflect benefits resulting from the use of deliberative approaches.

Among the explanations for this lack of performance improvement, one can evoke the timescale for effects on performance to happen. The duration of the experiment was short. Such a limited exposure to RBs is sufficient to convey effects on aspects of the learning experience (see above), but not on the final mark.

It is also possible that the tested combination of RBs is not adequate and that a more intensive use of some of them could have had effects traceable in the score at the test. However, the baseline intention of this experiment was not to produce a comparison between RBs but to contrast a regular learning activity system to a "reflection-inside" one that deliberately gives a face value to thinking processes. A detailed monitoring of each RB's contribution to performance would command a different experimental setting.

A third account to the absence of observed effects on learning outcomes might lie in the trap that the designed RBs become mechanical. Yet, in the context of this study, making a shallow use of affordances designed to deepen reflection and learning is indeed a possibility left to the students. This can be dictated by a lack of familiarity with reflection, an ignorance of its benefit, a strategic calculation, boredom after repeated applications, etc. The ease to "bypass" the reflective episodes is especially conspicuous in the case of the self-assessment tool (because it requires from participants "just" to tick one option out of 5 , an action which can be thoughtful or skipped through) but obviously exists as well with the 2 other types of 
breaks. To provide a detailed reporting on what pupils actually "do" with the RBs (scratch the surface versus invest in mindfulness) will require additional research efforts.

\section{Limitations}

The findings in this paper are subject to at least 2 limitations. First, the data stems from a relatively small number of participants. A larger sample size would have provided more statistical power.

The quantitative orientation taken in this research can be considered as a second caveat. This choice is indeed in accordance with the chief concerns of the setting: to establish the conditions of a permanent criss-crossing between an ongoing learning processes and explicit/structured episodes of reflection (no matter how the individual inner workings of this reflection takes place). A quantitative methodology allows to make sure that these back-andforth moves took place and to explore their impact. The downside is that it keeps at bay the properly individual and subjective dimension of reflection. To tackle it, other instruments and methodologies - out of the initial scope of the study - should enrich the research effort. These could for instance be an analysis of the questions produced with the "Question break", a think-aloud procedure conducted during the "Evocation break", a request for justification in the context of the "Self-assessment break", etc. The contrasted results obtained plead for complementary qualitative inquiries that would give insights into the actual engagement with the RBs and into the quality level of the prompted reflection (here supposed to be derived from the performance tests).

\section{Conclusion and future work}

This study explored the potential of one possible method to promote reflection: the reflection breaks meant to induce regular mental tingling for evaluating one's own learning, nurturing internal feedback (Butler \& Winne, 1995) and maintaining active commitment to the task at hand. The experiment requested from students to perform brief thinking episode at a frequent pace in order to intensify the ongoing mental crisscrossing between learning and meta-learning, assumed to be a key feature of thoughtful learning (Verpoorten, Westera, \& Specht, 2012) and a signpost of intellectual activity and discipline (Sternberg, 1998). The 3 contrasted reflective operations (questioning, evoking, self-assessing) requested from the pupils are well-documented in pedagogical literature (see section “Tools”). The effort of this study was to have them supported by dedicated lightweight and agile portlets inserted at levelpage in an online course provided on the open-source platform Liferay. The portlets were 
additionally linked to a learning dashboard (Verpoorten, Westera, \& Specht, 2011b) meant to consolidate deliberate reflection and instantiate a possible form of "split screen teaching" (Claxton, 2007).

The pattern of findings suggests that the benefit of a one-hour hand-on session with these RBs is not to be found in an enhanced cognitive performance but in an increased awareness of and an intensified presence to the learning process itself. The effects of RBs seem to occur in perceptions and attitudes towards reflective learning. By putting the mere action of learning under scrutiny and by rendering reflection about it more explicitly and more understandably to the students, RBs might help participants to realize that they are learners and not only students, and that learning is more than performing (Piaget, 1978). In this renewed meta-cognitive awareness of reflection (Boyd \& Fales, 1983), the external learning assignment to expedite would turn to be in the eye of the students a complex activity they are part of and which entails the steady integration of specific reflective mental activities characterizing expert learners. The study delivers indications that RBs can contribute to the development of this self-as-a-learner consciousness (in contrast to the self-as-a-performer identity) by helping him/her to attend to learning processes with increased awareness.

This research also throws up questions in need of further investigation. The most compelling relates to the ways to personalise the opportunities to reflect. At this stage, the RBs provided in the course present as neutral, static and stand-alone artefacts that become available to all students in the same fixed order (except in Chapter 5 which offers choices). More research is needed to accommodate the RBs’ nature (Bartholomé, \& Bromme, 2009; Stadtler, \& Bromme, 2008), modalities (Hung, Yang, Fang, Hwang, \& Chen, 2014; Papadopoulos, Demetriadis, Stamelos, \& Tsoukalas, 2009), exposure time (Gama, 2004), pattern of interaction (reading/watching information, giving information, verbalising information, Saito, \& Miwa, 2007), learning event (Verpoorten, Poumay, \& Leclercq, 2007) supported by the reflection (Kauffman, Ge, Xie, \& Chen, 2008), role of tutors in the reflection process (Van den Boom, Paas, van Merrienboer, \& Van Gog, 2004), etc., to learners’ individual characteristics (abilities, shortages, preferences, dispositions, acceptance of reflection, etc.) and content domains (Hoffman, \& Spatariu, 2008; Stark, \& Krause, 2009). For instance, students who have already developed reflective habits might not need to be exposed to RBs or might need other types of RBs while students who are already struggling with the first-order learning task or students unfamiliar with reflection may perceive RBs as an additional burden even though these have been conceived to support their learning. An approach based on adaptive systems would deal with these variations by defining logical rules 
enabling timely presentation of reflective activities to specific profiles. Another possibility is to develop reflection-conductive/supportive milieus rich and flexible enough to cater for a diversity of needs and styles.

It was the choice of this work to explore RBs as solitary practice inserted in a selflearning task. How this kind of experience of an action/reflection alternate sequence could be incorporated and maintained into a longer tutorial (Cowan, 1998) or in an eBook is also a question for the future.

The distinctive qualities of different types of RBs are another important emerging issue. On the one hand, it would be meaningless to dispute that the thought processes elicited by the 3 RBs formats do differ, as well as the mode of interaction with them. The designed portlets precisely isolate and support, graphically and cognitively, these specific reflective behaviours to be practised while learning. On the other hand, this study puts in debate a convergence or a combined effect of these reflection stimuli. Further research should address both specific and generic effects of RBs. In order to act upon distinctive strengths and shortages in the mastery of content and reflective practice, there is undoubtedly a need for refined accounts of the benefits attached to different reflection affordances. More research could also inform the possibility that, beyond the efficacies of specialized RBs, their steady presence might promote an atmosphere of reflection that propagates through the whole learning experience.

\section{References}

Bannert, M. (2006). Effects of reflection prompts when learning with hypermedia. Journal of Educational Computing Research, 4, 359-375

Bannert, M., Hildebrand, M., \& Mengelkamp, C. (2009). Effects of a metacognitivesupport device in learning environments. Computers in Human Behavior, 25(4), 829-835.

Bartholomé, T., \& Bromme, R. (2009). Coherence formation when learning from text and pictures: What kind of support for whom? Journal of Educational Psychology, 101(2), 282-293.

Boud, D. (1990). Assessment and the promotion of academic values. Studies in Higher Education, 15(1), 101-111.

Boud, D., Keogh, R., \& Walker, D. (1985). Reflection, Turning Experience into Learning. London: Kogan Page. 
Boyd, D. \& Fales, A. (1983) Reflective learning: key to learning from experience. Journal of Human Psychology, 23 (2), 83-117.

Brown, P., Lauder, H. and Ashton, D. (2008). Education, Globalisation and the Knowledge Economy. London: Teaching and Learning Research Programme. Retrieved from http://www.tlrp.org/pub/documents/globalisationcomm.pdf

Brown-Frossard, R. (2012). Memorization Isn’t A Lot Of Hocus Pocus. The International TEYL (Teaching English to Young Learners) Journal. Retrieved from http://www.teyl.org/article14.html

Butler, A. C. (2010). Repeated Testing Produces Superior Transfer of Learning Relative to Repeated Studying. Journal of Experimental Pschology: Learning, Memory, and Cognition, 36, 1118-1133.

Butler, D. L., \& Winne, P. H. (1995). Feedback and self-regulated learning: A theoretical synthesis. Review of Educational Research Review, 65, 245-281.

Cashman, K. (2012). The pause principle: Step Back to Lead Forward. San Francisco, CA: Berrett-Koehler.

Chiazzese, G., Ottaviano, S., Merlo, G., Chiari, A., Allegra, M., \& Seta, L. (2006). Surfing hypertexts with a metacognition tool. Informatica, 30, 439-445.

Claxton, G. (2006). Expanding the capacity to learn: a new end for education? Opening keynote address of the British Educational Research Association Annual Conference, University of Warwick, UK. Retrieved from http://www.guyclaxton.com/documents/New/BERA\%20Keynote\%20Final.pdf

Claxton, G. (2007). Expanding young people’s capacity to learn. British Journal of Educational Studies, 55(2), 1-20.

Cowan, J. (1998). On Becoming an Innovative University Teacher. Open University Press, Buckingham.

Di Vesta, F. J., \& Smith, D. A. (1979). The pausing principle: Increasing the efficiency of memory for ongoing events. Contemporary Educational Psychology, 4(3), 288-296.

Egan, K. (2010). The Future of Education: Reimagining Our Schools from the Ground Up: Yale University Press.

Entwistle, N. (2001). Promoting deep learning through teaching and assessment: conceptual frameworks and educational contexts. Paper presented at the TLRP Conference, Leicester, UK. Retrieved from http://www.tla.ed.ac.uk/etl/docs/entwistle2000.pdf

Ertmer, P., \& Newby, T. (1996). The expert learner: strategic, self-regulated, and reflective. Instructional Science, 24, 1-24. 
CCC \& GGG, 2007

Flesch, R. (1948). A new readability yardstick. The Journal of applied psychology, 32(3), 221-233.

Fredriksson, U., \& Hoskins, B. (2007). The development of learning to learn in a European context. Curriculum Journal, 18(2), 127-134.

Fulwiler, T., \& Young, A. (2000). Language Connections: Writing and Reading Across the Curriculum. WAC Clearinghouse Landmark Publications in Writing Studies. Urbana, Illinois: NCTE.

Gama, C. (2004). Metacognition in interactive learning environments: the reflection assistant model. In J.C. Lester, R. M. Vicario \& F. Paraguaçu (Eds.), Proceedings of the 7th International Conference on Intelligent Tutoring Systems, ITS 2004 (pp. 668-677). Berlin: Springer.

Gill, G., \& Halim, N. (2006). Reflection in action: Examining the place, impact and management issues surrounding the integration of reflection in classroom practice. Paper presented at the Association of Australian Research in Education (AARE) Conference. Retrieved from http://www.aare.edu.au/06pap/gil06021.pdf

Hoffman, B., \& Spatariu, A. (2008). The influence of self-efficacy and metacognitive prompting on math problem-solving efficiency. Contemporary Educational Psychology, 33(4), 875-893.

Hung, I. C., Yang, X. J., Fang, W. C., Hwang, G. J., \& Chen, N. S. (2014). A context-aware video prompt approach to improving in-field reflection levels of students. Computers \& Education, 70(1), 80-91.

Joseph, N. (2003). Metacognitive awareness: investigating theory and practice. Academic Exchange Quarterly. Retrieved from http://www.thefreelibrary.com

Karpicke, J., Butler, A., \& Roediger, H. (2009). Metacognitive strategies in student learning: Do students practise retrieval when they study on their own? Memory. 17(4), 471-479

Kauffman, D. F., Ge, X., Xie, K., \& Chen, C.-H. (2008). Prompting in web-based environments: Supporting self-monitoring and problem solving skills in college students. Journal of Educational Computing Research, 38(2), 115-137.

Krathwohl, D.R., Bloom, B.S., \& Masia, B.B. (1964). Taxonomy of educational objectives: Handbook II: Affective domain. New York: David McKay Co.

La Garanderie, A. (1989). Défense et illustration de l'introspection [Defense and illustration of introspection]. Paris : Le Centurion. 
Logtenberg, A., van Boxtel, C., \& van Hout-Wolters, B. (2011). Stimulating Situational Interest and Student Questioning through Three Types of Historical Introductory Texts. European Journal of Psychology of Education, 26(2), 179-198.

Loughran, J.J. (1996) Developing Reflective Practice: Learning about Teaching and Learning through modelling. London: Falmer.

Marbach-Ad, G., \& Sokolove, P. G. (2000). Can undergraduate biology students learn to ask higher level questions? Journal of Research in Science Teaching, 37(8), 854-870.

McAlpine, M. (2002). A summary of methods of Item analysis. Bluepaper Number 2, $\begin{array}{llll}\text { University of } & \text { Glasgow. } & \text { Retrieved }\end{array}$ http://www.caacentre.ac.uk/dldocs/BP2final.pdf

McCraty, R., Atkinson, M., Tomasino, D., Goelitz, J., \& Mayrovitz, H. (1999). The impact of an emotional self-management skills course on psychosocial functioning and autonomic recovery to stress in middle school children. Integrative Physiological and Behavioral Science, 34(4), 246-268.

McGuinness, C. (1999). From Thinking Skills to Thinking Classrooms: A Review and Evaluation of Approaches for Developing Pupils’ Thinking. DfEE Research Report RR115. Norwich: HMSO.

McKenzie, L.M. (2010). PERHAPS? Exploring Possibilities for Reflective Practice. Paper presented at the 16th International Reflective Practice Conference, Putteridge Bury Campus, University of Bedforshire. Retrieved from http://uplace.org.uk:8080/dspace/handle/10293/506

Nicol, D. J., \& MacFarlane-Dick, D. (2006). Formative assessment and self-regulated learning. A model and seven principles of good feedback practice. Studies in Higher Education, 31(2), 199-216.

Papadopoulos, P., Demetriadis, S., Stamelos, I., \& Tsoukalas, I. (2009). Prompting students’ context-generating cognitive activity in ill-structured domains: does the prompting mode affect learning? Educational Technology Research \& Development, 57(2), 193210.

Parker, D. (1994). Improving instruction for students with learning disabilities: the pause procedure. Retrieved from http://sped.usu.edu/assets/Master/thesis-library/ParkerD_Creative-Project_2004.pdf.

Pedrosa de Jesus, H., \& Moreira, A. C. (2009). The role of students' questions in aligning teaching, learning and assessment: a case study from undergraduate sciences. Assessment \& Evaluation in Higher Education, 34(2), 193-208. 
Piaget, J. (1978). Success and Understanding. Cambridge, Mass.: Harvard University Press.

Rowe, M. (1976). The pausing principle - Two invitations to inquiry. Research on College Science Teaching, 5, 258-259.

Rowe, M. (1986). Wait Time: Slowing Down May Be a Way of Speeding UP! Journal of Teacher Education, Jan-Feb., 43-49.

Ruhl, K. L., Hughes, C. A., \& Schloss, P. J. (1987). Using the Pause Procedure to Enhance Lecture Recall. Teacher Education and Special Education: The Journal of the Teacher Education Division of the Council for Exceptional Children, 10(1), 14-18.

Saito, H., \& Miwa, K. (2007). Construction of a learning environment supporting learner's reflection: A case of information seeking on the Web. Computers \& Education, 49(2), 214-229.

Schön, D. (1983). The Reflective Practitioner: How professionals think in action. London: Temple Smith.

Schraw, G., \& Dennison, R. (1994). Assessing metacognitive awareness. Contemporary Educational Psychology, 19, 460-475.

Seel, N. M. (2001). Epistemology, situated cognition, and mental models: Like a bridge over troubled water. Instructional Science, 29(4), 403-427.

Simpson, W. (2004). The pause method in undergraduate auditing: An analysis of student assessments and relative effectiveness. In J. Ketz (Ed.), Advances in Accounting Education Teaching and Curriculum Innovations (Vol. 6, pp. 69-85). Bingley, UK: Emerald Group Publishing Limited.

Stadtler, M., \& Bromme, R. (2008). Effects of the metacognitive computer-tool met.a.ware on the web search of laypersons. Computers in Human Behavior, 24(3), 716-737.

Stark, R., \& Krause, U.-M. (2009). Effects of reflection prompts on learning outcomes and learning behaviour in statistics education. Learning Environments Research, 12(3), 209-223.

Sternberg, R. J. (1998). Metacognition, abilities, and developing expertise: What makes an expert student? Instructional Science, 26(1), 127-140.

Taras, M. (2002). Using Assessment for Learning and Learning from Assessment. Assessment \& Evaluation in Higher Education, 27(6), 501-510.

Thompson, C. (2009). Metacognitive Strategies of Teaching and Learning in Introductory Psychology Classes. Paper presented at the 3rd National Conference on Innovations in the Scholarship of Teaching and Learning at Liberal Arts Colleges. 
Van den Boom, G., Paas, F., van Merrienboer, J., \& van Gog, T. (2004). Reflection prompts and tutor feedback in a Web-based learning environment: Effects on students' selfregulated learning competence. Computers in Human Behavior, 20, 551-567.

Veenman, M., Van Hout-Wolters, B., \& Afflerbach, P. (2006). Metacognition and learning: conceptual and methodological considerations. Metacognition and Learning, 1(1), 314.

Vermersch, P. (2009). Describing the Practice of Introspection. Journal of Consciousness Studies, 16(10/12), 20-57.

Verpoorten, D., Poumay, M. \& Leclercq, D. (2007). The 8 Learning Events Model: a Pedagogic Conceptual Tool Supporting Diversification of Learning Methods Experienced by the Online Student. Interactive Learning Environments, 15(2), 151160, 2007. Retrieved from http://hdl.handle.net/2268/10129

Verpoorten, D., Westera, W., \& Specht, M. (2011a). Reflection amplifiers in online courses: a classification framework. Journal of Interactive Learning Research, 22(2), 167-190. Retrieved from http://hdl.handle.net/2268/151374

Verpoorten, D., Westera, W., \& Specht, M. (2011b, 20 September). A first approach to "Learning Dashboards" in formal learning contexts. Paper presented at the ADVTEL workshop (1st International Workshop on Enhancing Learning with Ambient Displays and Visualization Techniques) at EC-TEL 2011, Palermo, Italy. Retrieved from http://hdl.handle.net/2268/151988

Verpoorten, D., Westera, W., \& Specht, M. (2012). Using reflection triggers while learning in an online course. British Journal of Educational Technology, 43(6), 1030-1040. Retrieved from http://orbi.ulg.ac.be/handle/2268/151799

Verpoorten, D., Castaigne, J.-L., Westera, W., \& Specht, M. (2012). A quest for metalearning gains in a physics serious game. Education and Information Technologies, 114. Retrieved from http://orbi.ulg.ac.be/handle/2268/151345

Weir, C. (1998). Using Embedded Questions to Jump-start Metacognition in Middle School Remedial Readers. Journal of Adolescent \& Adult Literacy, 4, 458-467. 


\section{Running head: STRUCTURED REFLECTION BREAKS IN AN ONLINE COURSE}

\section{APPENDIX 1}

The performance test comprised 10 multiple choice questions (the right answer is given below in italics) used in the online course "Sex and the Evolution" (CCC \& GGG, 2007) and 3 open questions based on the interpretation of picture in the light of the studied material.

\section{Multiple choice questions}

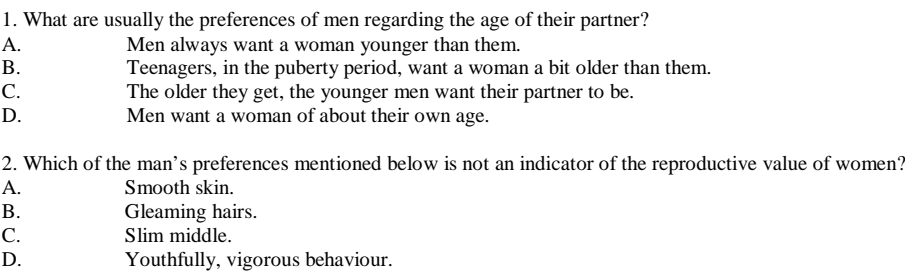

3. Among the following answers mentioned below, which one approaches the best the preferences of women with respect to her partner?

A. assured, offering exclusive attention, discrete and empathic

B. well dressed, romantic, rich and generous.

C. pleasant attitude to children, ambitious, attentive, open and careful.

D. depending on the context, all the above.

4. If we inspect the general partner preferences of men and women, which of the following statements is not true?

A. Women value the income of their partner more than men do, but men nevertheless grant it an important value.

B. Men and women find it both important that their partner has a philosophy of life similar to their own conceptions.

C. As for partners selection, women put intelligence at the first place while men give priority to physical attractiveness. Sense of humor is highly praised by men and women and they attach to it approximately just as much value.

5. Why, in mankind, are women choosier than men when it comes to the selection of a partner?

A. because this is necessary for the survival of their offspring.

B. because men are uncertain of their paternity.

C. because a short-term strategy is for men self-evident. because men always feel like having sex.

6. When we look at dating sits, then we can observe that...

A. $\quad$ women more rapidly react when a man defines himself as physically attractive.

B. homosexual women particularly emphasize their male properties.

C. women prefer not to describe their physical appearance otherwise men take it as a sexual invitation.

homosexual men pay attention to the same elements of the dating profiles than heterosexual men.

7. Which of the following statements is true with regard to relationships modes?

A. Where polygyny is permitted, it occurs only when men have sufficient resources.

B. Polyandry occurs more often than polygyny, but monogamy is still the most attentive partnership mode.

C. Polyandry occurs very sporadically and exclusively when men have developed a high certainty over their paternity.

D. When women have more resources than men, polyandry occurs more often than polygyny.

8. Humans seem predominantly monogamous. How is this monogamy best defined?

A. social monogamy

B. $\quad$ sexual monogamy

D. both A and C

9. When we follow only the theory of Trivers concerning parental investment differences between man and woman, then applies to humans that...

A. a man earns more money, and this is necessary for the offspring.

B. the contribution of the man to the offspring is essential.

C. the parental investment of the man is a nice useful extra

10. From an evolutionary perspective, our Western beauty ideal is mainly, with respect to woman's physical aspect...

A. a characteristic of the woman.

B. a preference of the man.

C. a choice of the woman.

a sign of emancipation.

Open questions

Open questions
Based on what you have studied in the course, give a possible interpretation of the pictures in terms of evolutionary psychology (translation for the third picture: "The one who is not strong must be smart, an artist or funny").
must

\section{$<$ FIGURE 8 NEAR HERE $>$}

